Military Technical College

Kobry El-Kobbah, Cairo, Egypt

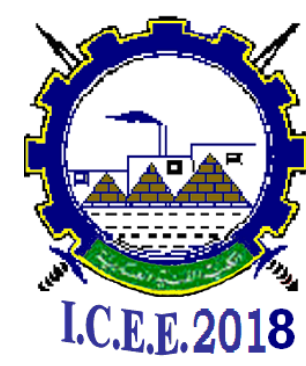

$9^{\text {th }}$ International Conference on

Chemical \& Environmental

Engineering

3-5 April 2018

\title{
SAN-1
}

\section{Nanoparticles-based heterogenous catalysts for the continuous production of Biodiesel}

By

\author{
Mohamed S. El-Deab
}

\begin{abstract}
Sustainable and renewable energy resources are highly essential to replace the progressively depleting fossil fuel based energy sources. Biofuels play a vital role in minimizing $\mathrm{CO}_{2}$ emission, and reducing global warming. Biodiesel has become attractive since it is biodegradable, renewable and nontoxic. Biodiesel chemically known as fatty acid methyl ester (FAME) that displays good oil qualities, including higher cetane number, higher combustion efficiency and less emission. Transesterification of vegetable oils and animal fats and/or Esterification of fatty acids are the easiest and most cost-effective approach to produce biodiesel. In this context, nanomaterials have been identified as the key to unlocking a new generation of materials that can be used as catalysts in energy conversion and storage devices due to their numerous advantages as the high surface to volume ratio which increases the overall performance, while minimizing the cost of often expensive metal and alloy constituents.

The main objective of this study is the continuous production of biodiesel from vegetable oil via transesterification process and/or from fatty acids via esterification process using nanoparticle-based modified catalysts. The preliminary results showed a promising yield of biodiesel using cheap heterogenous catalysts; the results will be displayed and discussed in this talk.
\end{abstract}

Department of Chemistry, Faculty of Science, Cairo University, Cairo, Egypt

*Corresponding author: msaada68@yahoo.com 